\title{
Microstructure stability of silver electrodeposits at room temperature
}

\author{
Hansen, Karsten; Pantleon, Karen
}

Published in:

Scripta Materialia

Link to article, DOI:

10.1016/j.scriptamat.2007.09.033

Publication date:

2008

Document Version

Publisher's PDF, also known as Version of record

Link back to DTU Orbit

Citation (APA):

Hansen, K., \& Pantleon, K. (2008). Microstructure stability of silver electrodeposits at room temperature. Scripta Materialia, 58, 96-98. https://doi.org/10.1016/j.scriptamat.2007.09.033

\section{General rights}

Copyright and moral rights for the publications made accessible in the public portal are retained by the authors and/or other copyright owners and it is a condition of accessing publications that users recognise and abide by the legal requirements associated with these rights.

- Users may download and print one copy of any publication from the public portal for the purpose of private study or research.

- You may not further distribute the material or use it for any profit-making activity or commercial gain

- You may freely distribute the URL identifying the publication in the public portal

If you believe that this document breaches copyright please contact us providing details, and we will remove access to the work immediately and investigate your claim. 


\title{
Microstructure stability of silver electrodeposits at room temperature
}

\author{
Karsten Hansen and Karen Pantleon* \\ Technical University of Denmark, Department of Manufacturing Engineering and Management, Kemitorvet b. 204, \\ DK-2800 Kgs. Lyngby, Denmark
}

Received 13 July 2007; revised 10 September 2007; accepted 24 September 2007 Available online 22 October 2007

\begin{abstract}
In situ quantitative X-ray diffraction analysis was used to investigate the kinetics of microstructure evolution at room temperature (self-annealing) in an electrodeposited silver layer. As a function of time at room temperature the as-deposited nanocrystalline microstructure evolved considerably: orientation-dependent grain growth and changes of the preferred grain orientation occurred. It is demonstrated for the first time that self-annealing occurs for electrodeposited silver layers and, hence, is not a unique feature of copper as often suggested.
\end{abstract}

(C) 2007 Acta Materialia Inc. Published by Elsevier Ltd. All rights reserved.

Keywords: Self-annealing; Electroplating; Texture; Grain growth; Silver

Silver is increasingly attracting attention as a potential interconnect material $[1,2]$ and the replacement of copper by silver in the future is being discussed in similar terms to those previously used for the changeover from aluminum-based materials to copper. Indeed, the lower electrical resistivity of bulk silver compared to bulk copper is promising; however, the properties finally depend on the microstructure of the films. For electrodeposited copper it is well known that the as-deposited microstructure is not stable, but evolves as a function of time at room temperature (self-annealing) (e.g. [3-6]), and changes may continue at elevated temperatures $[7,8]$. The microstructural evolution during self-annealing of copper electrodeposits is accompanied by considerable improvements in the electrical conductivity and electromigration resistance, and is hence of importance for the functionality of copper interconnects.

For silver electrodeposits, the thermal stability of the microstructure and associated properties has been investigated at elevated temperatures $[9,10]$, but to the knowledge of the authors, self-annealing of silver layers at room temperature has not been reported previously. So far, evolution of the microstructure at room temperature has only been observed in bulk nanocrystalline

\footnotetext{
* Corresponding author. Tel.: +45 4525 2207; fax: +45 4593 6213; e-mail: pantleon@ipl.dtu.dk
}

materials during mechanical loading [11-14] or in thin copper films [3-6,15].

Silver was electrodeposited from a commercial cyanide electrolyte (Engbright) containing $45 \mathrm{~g}^{-1} \mathrm{AgCN}$, $165 \mathrm{~g}^{-1} \mathrm{KCN}, 15 \mathrm{~g}^{-1} \mathrm{~K}_{2} \mathrm{CO}_{3}$ and appropriate additive concentrations (Engbright S101 and S201). The bath temperature was $21^{\circ} \mathrm{C}$. A $4 \mu \mathrm{m}$ thick silver layer was deposited with a current density of $2.75 \mathrm{~A} \mathrm{dm}^{-2}$ on a copper sheet.

For investigating the kinetics of self-annealing in situ $\mathrm{X}$-ray diffraction (XRD) analysis was started immediately after the silver layer was deposited, cleaned, dried and mounted in the X-ray diffractometer (Discover D8, Bruker AXS), i.e. within about 15 min after deposition. $\mathrm{CuK} \alpha$ radiation was used to measure the diffraction lines corresponding to (111), (200) and (222) lattice planes. Line profiles were fitted by applying pseudoVoigt functions and microstructure information in terms of grain size and microstrain was obtained by applying both the single-line method [16] and the WilliamsonHall method [17] after correction for instrumental line broadening. In addition to repeated measurements of various diffraction lines, quantitative crystallographic texture analysis was also performed in turn with the line scans. For texture analysis, 111 and 220 pole figures were recorded (measurements were restricted to quarters of the pole figures, which are representative due to the presence of fibre textures) and the orientation distribution function was calculated. Scans of the various 


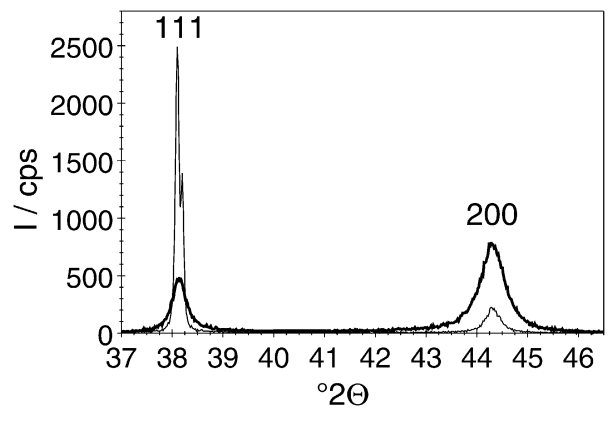

Figure 1. Diffraction lines from (111) and (200) lattice planes parallel to the surface measured about 15 min after deposition (thick drawing) and two weeks after deposition (thin drawing).

XRD lines and crystallographic texture analysis were performed repeatedly in turn until the recorded data stabilized. For the present example, in situ XRD studies were continued over a period of more than two weeks without any interruption.

The widths and intensities of the measured diffraction line profiles changed drastically as a function of time at room temperature (see Figs. 1 and 2).

Pseudo-Voigt fitting revealed pure Lorentzian shapes ${ }^{1}$ of the diffraction line profiles, and hence it is suggested that the line broadening is mainly affected by the size of coherently diffracting domains (interpreted as grain size). The conclusion that microstrain does not contribute significantly to line broadening is supported by the evaluation of the $h h h$ diffraction lines. Identical grain sizes were calculated from both the 111 and the 222 single-line profiles. The Williamson-Hall plot using only the 111 and 222 reflections yielded horizontal curves, indicating that no dependence of the line width on the diffraction angle, and, thus, no measurable influence of microstrain for $\langle 111\rangle$ oriented grains were observed.

The as-deposited microstructure consisted of nanocrystalline grains with only slight orientation dependence (cf. Fig. 3). After a short incubation time considerable growth of grains with $\langle 111\rangle$ orientation occurred and grain sizes approached (and certainly exceeded) the maximum values quantifiable under the applied XRD conditions (cf. [18]). In contrast, only negligible growth of $\langle 100\rangle$ oriented grains occurred and after two weeks the $\langle 100\rangle$ grains were only about $30 \mathrm{~nm}$.

The evolution of the as-deposited microstructure by grain growth during self-annealing is accompanied by changes of the dominant grain orientation as indicated by the observed kinetics of the integrated intensities (Fig. 2b) and quantitative texture analysis (Fig. 4). For the as-deposited silver layer a single $\langle 100\rangle$ fibre texture was present (Fig. 4a). This $\langle 100\rangle$ texture with a rather strong as-deposited orientation density of 5.0 became weaker during self-annealing and at the same time a $\langle 211\rangle$ texture developed. About two weeks after deposition the $\langle 211\rangle$ texture became very broad and reached an orientation density of 3.9 (Fig. 4b).

\footnotetext{
${ }^{1}$ Slight Gaussian contributions were detected only for the very first measurements after deposition.
}


Figure 2. (a) Full width at half maximum (FWHM), and (b) integrated intensity, $I_{\text {int }}$, at room temperature as a function of time, $t$, after deposition. Data corresponding to the 111 diffraction lines (black squares) and 200 diffraction lines (grey triangles) are shown.

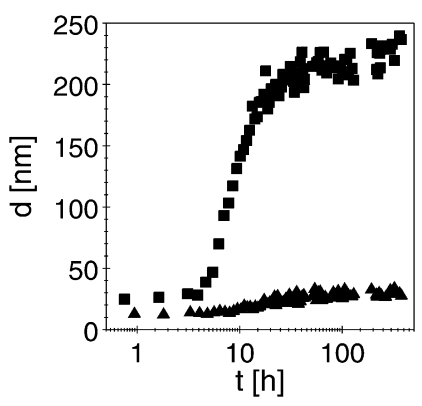

Figure 3. Grain size, $d$, of $\langle 111\rangle$ (squares) and $\langle 100\rangle$ (triangles) oriented grains calculated from the widths of 111 and 200 diffraction lines measured as function of time, $t$ (cf. Fig. 2a).
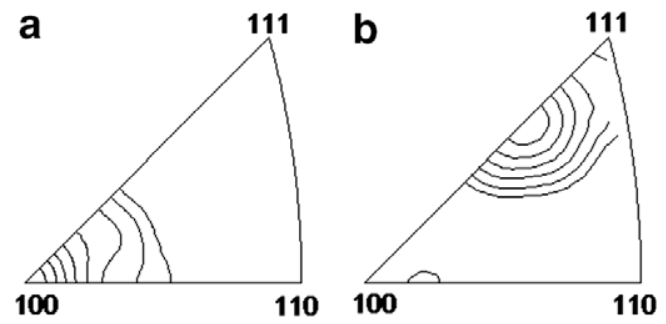

Figure 4. Inverse pole figures in normal direction of the silver layer asdeposited (a) and two weeks after deposition (b). Levels: 1.0, 1.5, 2.0, $2.5,3.0,3.5,4.0,4.5$.

The present work clearly demonstrates that selfannealing also occurs for electrodeposited silver layers, and hence is not a unique feature of copper as often suggested.

Self-annealing in silver electrodeposits shows some similarities to the well known self-annealing behavior of electrodeposited copper layers. For both materials the as-deposited microstructure consisting of nanocrystalline grains with strong preferred grain orientations transforms during room temperature storage into a self-annealed microstructure with considerably larger grains and altered preferred orientations-however, some remarkable differences in the self-annealing behavior of the two materials were observed. For both copper and silver electrodeposits the kinetics of self-annealing was found to depend on the film thickness (not shown here) and the grain orientation. For both materials, grains not constituting the dominant orientation in the 
as-deposited microstructure grow first: for copper, these are the $\langle 100\rangle$ oriented grains in the as-deposited strongly $\langle 111\rangle$ oriented microstructure, and for silver, these are the $\langle 111\rangle$ grains in the as-deposited microstructure with preferred $\langle 100\rangle$ orientation. In contrast to copper, where grains of the major texture component (the $\langle 111\rangle$ grains) also finally grow, albeit at a slightly later stage $[3,4]$, in silver, electrodeposited grains with the dominant as-deposited orientation (the $\langle 100\rangle$ grains) remain almost unaffected for quite long times, at least within the period of investigation. A further peculiarity of self-annealing in silver is the evolution of a new strong crystallographic texture simultaneously with the weakening of the as-deposited preferred orientation, whereas copper electrodeposits $[3,4]$ tend to become randomly oriented during self-annealing.

The results indicate the importance of the as-deposited crystallographic texture for the kinetics of the microstructure evolution at room temperature.

Based on the observed kinetics of grain growth and crystallographic texture changes during room temperature storage of electrodeposited silver it is concluded that any successful application of silver layers must allow for the effect of self-annealing on the microstructure.

The authors wish to thank Christian Ravn (IPU) for experimental help during electrodeposition and Marcel A.J. Somers (IPL, DTU) for valuable discussions. The Danish Research Agency is acknowledged (Grant 1603-0276) for financial support.

[1] T.P. Moffat, B. Baker, D. Wheeler, J.E. Bonevich, M. Edelstein, D.R. Kelly, L. Gan, G.R. Stafford, P.J. Chen, W.F. Egelhoff, D. Josell, J. Electrochem. Soc. 149 (2002) C423-C428.
[2] M. Hauder, W. Hansch, J. Gstötter, D. Schmitt-Landsiedel, Solid-State Electron. 47 (2003) 1227-1231.

[3] K. Pantleon, M.A.J. Somers, Scripta Mater. 55 (2006) 283-286.

[4] K. Pantleon, M.A.J. Somers, J. Appl. Phys. 100 (2006) 114319-01-114319-07.

[5] J.M.E. Harper, C. Cabral Jr., P.C. Andricacos, L. Gignac, I.C. Noyen, K.P. Rodbell, C.K. Hu, J. Appl. Phys. 86 (1999) 2516-2525.

[6] S. Lagrange, S.H. Brongersma, M. Judelewicz, A. Saerens, I. Vervoort, E. Richard, R. Palmans, K. Maex, Microelectron. Eng. 50 (2000) 449-457.

[7] Dong Nyung Lee, Hyo Jong Lee, J. Electron. Mater. 32 (2003) 1012-1022.

[8] Hyo Jong Lee, Heung Nam Han, Dong Nyung Lee, J. Electron. Mater. 34 (2005) 1493-1499.

[9] Hyo-Seung Nam, Dong Nyung Lee, J. Electrochem. Soc. 146 (1999) 3300-3308.

[10] T.L. Alford, L. Chen, K.S. Gadre, Thin Solid Films 429 (2003) 248-254.

[11] M. Jin, A.M. Minor, E.A. Stach Jr., J.W. Morris, Acta Mater. 52 (2004) 5381-5387.

[12] K. Zhang, J.R. Weertman, J.A. Eastman, Appl. Phys. Lett. 87 (2005) 061921-1-061921-3.

[13] G.J. Fan, L.F. Fu, D.C. Qiao, H. Choo, P.K. Liaw, N.D. Browning, Scripta Mater. 54 (2006) 2137-2141.

[14] G.J. Fan, Y.D. Wang, L.F. Fu, H. Choo, P.K. Liaw, Y. Ren, N.D. Browning, Appl. Phys. Letters 88 (2006) 171914-1-171914-3.

[15] C. Detavernier, D. Deduytsche, R.L. Van Meirhaeghe, J. De Baerdemaeker, C. Dauwe, Appl. Phys. Lett. 82 (2003) $1863-1865$.

[16] T.H. de Keijser, J.I. Langford, E.J. Mittemeijer, A.B.P. Vogels, J. Appl. Cryst. 15 (1982) 308-314.

[17] G.K. Williamson, W.H. Hall, Acta Metall. 1 (1953) 22 31.

[18] K. Pantleon, A. Gholinia, M.A.J. Somers, Phys. Status Solidi (A), accepted for publication, 2007. 